\title{
Sources and characteristics of HULIS and other organic aerosol components in Beijing: Results from offline-AMS and FT-IR analyses
}

\author{
R.C. ZHOU ${ }^{1}$, Q.C. $\mathrm{CHEN}^{2}$, J. $\mathrm{CHEN}^{3}$, P.Q. Fu ${ }^{4}$, \\ Y.G. DENG ${ }^{1}$, P. VODICKA ${ }^{5}$, D.K. DESHMUKH ${ }^{5}$, \\ K. KAWAMURA ${ }^{5}$ AND M. MOCHIDA ${ }^{1,6 *}$
}

${ }^{1}$ Grad. Sch. Environ Stud., Nagoya Univ., Nagoya, Japan ${ }^{2}$ Shaanxi Univ. Sci. Technol., Xi'an, China

${ }^{3}$ Sch. Environ Sci. Eng., Tianjin Univ., Tianjin, China

${ }^{4}$ Inst. Surf-Earth Syst. Sci., Tianjin Univ., Tianjin, China

${ }^{5}$ Chubu Inst. Adv. Stud., Chubu Univ., Kasugai, Japan

${ }^{6}$ Inst. Space-Earth Environ. Res., Nagoya Univ., Nagoya, Japan (*correspondence: mochida@isee.nagoya-u.ac.jp)

Anthropogenic atmospheric aerosol is closely linked to global environmental problems through its role on the Earth's radiative balance and human health. Studying the sources and characteristics of aerosol can help us better understand its impact on the environment and make appropriate control strategies. In this study, solvent extraction and solid-phase extraction were used to separate organic aerosol (OA) into humic-like substance (HULIS), a high-polar fraction of water soluble organic matter (HP-WSOM), and water insoluble organic matter (WISOM), and they were characterized using a high resolution aerosol mass spectrometer (HR-AMS) and a Fourier transform infrared (FT-IR) spectrometer. HP-WSOM was the most abundant fraction with a high $\mathrm{O} / \mathrm{C}$ ratio (1.13). HULIS had a moderate $\mathrm{O} / \mathrm{C}$ ratio $(0.43)$ and contributed mainly by alkyl, nonacid carbonyl, hydroxyl and carboxyl groups. WISOM was dominated by alkyl group with a low $\mathrm{O} / \mathrm{C}$ ratio (0.13). Source apportionment was performed by positive matrix factorization (PMF) for all three fractions. Five factors, which are fossil fuel OA (FFOA), cooking-like OA (COA), biomass burning OA (BBOA), less-oxidized oxygenated OA (LO-OOA), and more-oxidized oxygenated OA (MO-OOA), were resolved. HULIS was found to be mainly contributed by partly-aged COA (54\%), which was not considered as an important source before, in addition to BBOA (32\%) and MO-OOA (10\%). HP-WSOM was almost fully contributed by two OOA factors (99\%), and WISOM was contributed mainly by FFOA $(79 \%)$. COA and BBOA were also identified in WISOM whereas they were the main contributors of HULIS. These results suggest that the PMF factors are associated with specific molecular structures. Further studies based on a laboratory-based fractionation of $\mathrm{OA}$ and an analysis using a receptor model could provide more insight into the relationship between the chemical structure and sources of OA. 